\title{
To tighten or loosen water quality effluent standards for pollutants?
}

\author{
Masaaki Hosomi
}

Published online: 13 May 2014

(C) Springer-Verlag Berlin Heidelberg 2014

Water quality control for rivers, lakes, seas, and groundwater in Japan is enforced by the Water Pollution Control Law, which sets the Environmental Quality Standard (EQS) for targeted water quality to preserve human health and the living environment. For 28 toxic substances including mercury and PCBs, uniform EQS values are applied all over the country. These standard values are at the same levels as those for tap water. On the contrary, eight specific items including BOD and COD have different standard values depending on utilization objectives of each water body. Fulfillment of EQS is evaluated by environmental monitoring at 5,400 points (216,000 samples) in rivers, lakes, and sea areas, and at about 10,000 points in groundwater.

Above all, items related to the protection of human health, i.e., toxic substances mainly in wastewaters discharged from various manufacturing plants with specific facilities, are subject to the National Effluent Standards for wastewaters (NES). According to NES, the concentration of each of these pollutants is generally set at 10 times as high as that required by EQS. The rationale for this is based on the fact that wastewaters from these plants are diluted by a factor of more than 10 in the receiving streams.

Specific facilities discharging wastewaters which contain toxic substances or wastewater constituents are regulated. Each facility is designated as belonging to a relevant category depending on types of manufacturing. For example, a research institute, for instance, my university, is classified as a cleaning facility. An organization that discharges polluted wastewater is required to (1) report the installation of a specified facility; (2) restrict discharge of

M. Hosomi ( $\square)$

Tokyo University of Agriculture and Technology, Tokyo, Japan e-mail: hosomimasaaki1130@gmail.com effluents; (3) restrict wastewater permeation to groundwater; and (4) measure the effluent discharge. Exceeding the effluent standards by NES and failure to measure can invite punishment (imprisonment or monetary penalty) to the organization. The regulation on punishment was tightened after revelation that some organizations practiced interpolation of data and other improper acts some years ago.

I have been a chairman of a special committee for wastewater regulation based on NES in the Ministry of the Environment for several years. Several committee meetings were held to propose a revised NES according to the reinforcement and deregulation of EQS. In August 2011, EQS for cadmium was reinforced, resulting in the environmental standard reducing from 0.01 down to $0.003 \mathrm{mg} /$ L. On the other hand, EQS for 1,1-dichloroethylene was deregulated from 0.02 to $0.1 \mathrm{mg} / \mathrm{L}$. According to the deregulation of 1,1-dichloroethylene in EQS, it was necessary to shortly revise NES. After no objection via public comments was obtained, a revised regulatory decision was adopted, eventually deregulating NES for 1,1-dichloroethylene from 0.2 to $1 \mathrm{mg} / \mathrm{L}$.

However, NES for cadmium, which is yet to be reinforced as of now (April 2014), requires a meticulous effort. Examining monitoring data all over the country and reviewing the data of pollutant release and transfer register (PRTR), it turned out that some specific facilities, subject to NES, would face a severe situation due to the reinforcement of EQS. They have been able to comply with the previous NES for cadmium concentration as high as $0.1 \mathrm{mg} / \mathrm{L}$; however, they would not be able comply with a newly set NES for cadmium if the NES were set at $0.03 \mathrm{mg} / \mathrm{L}$ according to the reinforcement of EQS (i.e., from 0.01 to $0.003 \mathrm{mg} / \mathrm{L}$ ). Setting the effluent standards of pollutants and enforcing compliance is a continuing challenge for attaining sustainable water policy. 